This article is licensed under the Creative Commons Attribution-NonCommercial 4.0 International License (CC BY-NC) (http://www.karger.com/Services/OpenAccessLicense) Usage and distribution for commercial purposes requires written permission.

\title{
Successful Conservative Treatment of Traumatic Intraperitoneal Bladder Rupture in a Child: A Case Report
}

\author{
Naoki Yogo ${ }^{a, b} \quad$ Chiaki Toidaa, ${ }^{a}$ Takashi Muguruma ${ }^{a, b}$

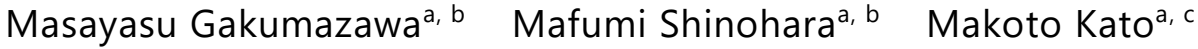 \\ Ko Takahashi ${ }^{a, c}$ Ichiro Takeuchi ${ }^{a, b}$ \\ aAdvanced Critical Care and Emergency Center, Yokohama City University Medical Center, \\ Yokohama, Japan; b Department of Emergency Medicine, School of Medicine, Yokohama \\ City University, Yokohama, Japan; 'Department of General Surgery, School of Medicine, \\ Yokohama City University, Yokohama, Japan
}

\section{Keywords}

Intraperitoneal bladder rupture $\cdot$ Child $\cdot$ Nonsurgical treatment $\cdot$ Blunt trauma $\cdot$ Pelvic fractures

\begin{abstract}
The urinary bladder is protected by the pelvic bones and hence is a site less susceptible to external force injury than other organs. As children's bones are not fully developed, the risk of bladder injury by external force is greater in children than adults. Pelvic fractures often cause the bladder to rupture, as do strong external forces when the bladder is filled. Bladder rupture is categorized as extraperitoneal or intraperitoneal, and treatments differ between the two. Extraperitoneal injury usually heals after drainage alone, whereas intraperitoneal injury usually requires surgical intervention such as a combination of surgical repairs and drainage. Herein, we report a pediatric case of intraperitoneal bladder rupture successfully treated without surgical repair (i.e., with drainage via an intraperitoneal tube and a urethral catheter only). Our
\end{abstract}


report suggests that nonoperative treatment is an option for pediatric patients with intraperitoneal bladder rupture if certain conditions are met.

\section{Introduction}

Bladder injuries are mostly caused by blunt trauma sustained in traffic accidents and rarely by penetrating trauma such as stab wounds $[1,2]$. Bladder rupture is classified as extraperitoneal or intraperitoneal based on the form of the rupture. Extraperitoneal bladder rupture (70-90\%) is more common than intraperitoneal bladder rupture (15-25\%) and both types together (5-12\%) [1,3]. Shear force on the bladder due to pelvic fractures is the main cause of extraperitoneal rupture [4], whereas a sudden increase in intra-abdominal pressure due to blunt trauma is the main cause of intraperitoneal rupture, which mostly occurs at the bladder dome [5, 6]. Extraperitoneal and intraperitoneal bladder ruptures are treated differently [7-9]. Although intraperitoneal bladder rupture usually requires surgical procedures [7], we herein report a pediatric case of intraperitoneal bladder rupture successfully treated via a nonoperative procedure.

\section{Case Report}

A 3-year-old boy with no medical history was injured in a traffic accident and transported to a primary care hospital. Fractures of the right iliac and pubic bones were diagnosed and treated conservatively during hospitalization. On day 2 postinjury, the patient was transferred to our hospital owing to urinary retention, abdominal distension, and suspected bladder injury on contrast-enhanced computed tomography (CT). Drowsy consciousness (Glasgow Coma Scale 14, E3V5M6) and tachypnea (respiratory rate 36 breaths/min) were noted. Oxygenation was slightly impaired, with an $\mathrm{SpO}_{2}$ level of $94 \%$ on oxygen at $10 \mathrm{~L} / \mathrm{min}$. Blood pressure was 131/76 $\mathrm{mm} \mathrm{Hg}$, and heart rate was 130 beats/min. Physical examination revealed significant abdominal distension, and arterial blood gas analysis revealed metabolic acidosis (pH 7.26, $\mathrm{PaCO}_{2} 37 \mathrm{~mm} \mathrm{Hg}, \mathrm{PaO}_{2} 319 \mathrm{~mm} \mathrm{Hg}, \mathrm{HCO}_{3}{ }^{-}-16.2 \mathrm{mEq} / \mathrm{L}$ ). In laboratory tests the following were above normal: white blood cell count $(14,800 / \mu \mathrm{L})$, prothrombin time/international normalized ratio (1.27), partial thromboplastin time (27.8 s), C-reactive protein $(1.9 \mathrm{mg} / \mathrm{dL})$, fibrin degradation product $(11.9 \mu \mathrm{g} / \mathrm{mL})$, and D-dimer $(5.3 \mu \mathrm{g} / \mathrm{mL})$ levels. On CT, bilateral pulmonary atelectasis, fractures of the right iliac and pubic bones, and contrast medium leakage from the urinary bladder were evident (Fig. 1). No obvious organ injury other than intraperitoneal bladder rupture requiring laparotomy was recognized using CT. Cystography using a urethral catheter showed injury of the bladder dome (Fig. 2).

Since the patient presented with drowsy consciousness, tachypnea, and tachycardia, tracheal intubation was performed. At the same time, a 10-Fr silicon catheter (Becton, Dickinson and Company) was inserted as the urethral catheter under radioscopy without resistance. Immediately following catheterization, $100 \mathrm{~mL}$ of hematuric urine was drained. Subsequently, hematuria was not noted for about $1 \mathrm{~h}$. Abdominal drainage was performed with an 8-Fr polyurethane pigtail catheter (CREATE MEDIC Inc.). Consequently, the amount of abdominal 
drainage via an intraperitoneal tube reached 1,100 $\mathrm{mL}$ and the abdominal distension and metabolic acidosis began to disappear. As the drainage had been effectively performed during the catheter insertion on day 3 postinjury, the patient was weaned from the ventilator and tracheal extubation was performed. On day 5 postinjury, the abdominal drainage catheter was removed after having confirmed that the drainage speed had become $<5-10 \mathrm{~mL} /$ hour. On day 12 postinjury, the urethral catheter was removed after cystography and showed no contrast medium leakage. On day 13 postinjury, the patient was returned to the primary care hospital for bed rest until the pelvic bone fractures had healed.

\section{Discussion}

In this paper we report a pediatric case of traumatic intraperitoneal bladder rupture with pelvic fracture that was successfully treated via conservative treatment without surgical repair.

Extraperitoneal bladder rupture usually heals after urethral catheterization alone. Only in specific cases, such as those involving bone fragments, rectal perforation, severe hematuria, or combined injuries requiring laparotomy, surgical repairs are needed. Intraperitoneal bladder rupture, on the other hand, is usually surgically repaired via laparotomy and urethral drainage owing to its low rate of spontaneous healing and the high risk of peritonitis, acidosis, and pseudo-renal failure with consequent electrolyte imbalance $[6,10]$.

There are many reports on the successful conservative treatment (i.e., urethral catheterization alone or in combination with percutaneous drainage catheterization) of iatrogenic intraperitoneal bladder rupture. Mulkey and Witherington [11] reported a case of bladder tumor, and Richardson and Leadbetter [12] reported a case of cervical carcinoma in an adult patient. Osman et al. [13] presented four pediatric cases of intraperitoneal bladder rupture with conservative treatment who had significantly shorter hospital stays (3-11 days) than cases involving surgical repairs (6-23 days). There are also case reports of successful conservative treatment of traumatic intraperitoneal bladder rupture in adult patients [14, 15]. Hayakawa et al. [14] presented a case of blunt traumatic intraperitoneal bladder rupture and severe pelvic fracture, which required transcatheter arterial embolization and bone fixation. In these cases, surgical repair for intraperitoneal bladder ruptures was not needed except for patients with other abdominal organ injuries. Conservative treatment was considered to have less likely resulted in infectious consequences and additional bleeding. Geng et al. [15] also reported a case of intraperitoneal bladder rupture without surgical repair using the urethral catheter alone. As the incidence of lower urinary tract injury in association with pelvic fracture is lower in children (1\%) than in adults $(10-25 \%)$ [8], pediatric patients may be more likely to become adapted to conservative treatment without surgical repairs in comparison to adult patients. Table 1 presents four cases of blunt trauma in pediatric patients with traumatic intraperitoneal bladder rupture with conservative treatment. Nonoperative treatment for traumatic intraperitoneal bladder rupture is appropriate in the following circumstances: (1) no organ injury that requires laparotomy, (2) availability of adequate drainage, and (3) no complications such as peritonitis. In summary, conservative treatment without laparotomy might become an optional treatment for intraperitoneal bladder rupture if certain conditions are 
Yogo et al:: Successful Conservative Treatment of Intraperitoneal Bladder Rupture in a Child

met. Our patient had traumatic intraperitoneal bladder rupture accompanied by pelvic fractures, but no injury to other organs was noted. Moreover, both urethral and abdominal drainage were extremely effective for intravesical decompression without infection and interventional complications. Our patient might have been cured through conservative therapy alone without surgical repairs, because these conditions were fortunately met.

The previously mentioned discussions, however, were based on only case series which contained few cases. Moreover, we found no evidence about the differences in the incidence rate of peritonitis and mortality rate compared between conservative management and surgical repairs. In addition, although patients with bladder rupture have a high mortality rate, close observation of the patients' conditions is essential to allow timely changes in treatment, including performance of surgical procedures if conservative management is chosen.

\section{Acknowledgment}

We thank Dr. Daiji Takamoto (Department of Urology and Renal Transplantation, Yokohama City University Medical Center) for providing medical support as a urologist.

\section{Statement of Ethics}

This study was approved by our ethics committee (Yokohama City University). Written informed consent was obtained from the patient's parents for publication of this case report.

\section{Disclosure Statement}

The authors have no conflicts of interest to declare.

\section{Funding Sources}

The authors have no funding sources.

\section{Author Contributions}

N. Yogo, C. Toida, and T. Muguruma conceptualized and designed the study. All authors collected and analyzed data. N. Yogo and C. Toida wrote the manuscript. I. Takeuchi provided technical support and conceptual advice. All authors read and approved the final manuscript. 
Yogo et al.: Successful Conservative Treatment of Intraperitoneal Bladder Rupture in a Child

\section{References}

1 Chan DP, Abujudeh HH, Cushing GL Jr, Novelline RA. CT cystography with multiplanar reformation for suspected bladder rupture: experience in 234 cases. AJR Am J Roentgenol. 2006 Nov;187(5):1296-302.

2 Morey AF, Iverson AJ, Swan A, Harmon WJ, Spore SS, Bhayani S, et al. Bladder rupture after blunt trauma: guidelines for diagnostic imaging. J Trauma. 2001 Oct;51(4):683-6.

3 Vaccaro JP, Brody JM. CT cystography in the evaluation of major bladder trauma. Radiographics. 2000 Sep-Oct;20(5):1373-81.

4 Santucci RA, Wessells H, Bartsch G, Descotes J, Heyns CF, McAninch JW, et al. Evaluation and management of renal injuries: consensus statement of the renal trauma subcommittee. BJU Int. 2004 May;93(7):937-54.

5 Peters PC. Intraperitoneal rupture of the bladder. Urol Clin North Am. 1989 May;16(2):279-82.

6 Hochberg E, Stone NN. Bladder rupture associated with pelvic fracture due to blunt trauma. Urology. 1993 Jun;41(6):531-3.

7 Corriere JN Jr, Sandler CM. Management of the ruptured bladder: seven years of experience with 111 cases. J Trauma. 1986 Sep;26(9):830-3.

8 Tarman GJ, Kaplan GW, Lerman SL, McAleer IM, Losasso BE. Lower genitourinary injury and pelvic fractures in pediatric patients. Urology. 2002 Jan;59(1):123-6; discussion 126.

9 Cass AS, Luxenberg M. Features of 164 bladder ruptures. J Urol. 1987 Oct;138(4):743-5.

10 Hsieh CH, Chen RJ, Fang JF, Lin BC, Hsu YP, Kao JL, et al. Diagnosis and management of bladder injury by trauma surgeons. Am J Surg. 2002 Aug;184(2):143-7.

11 Mulkey AP Jr, Witherington R. Conservative management of vesical rupture. Urology. 1974 Oct;4(4):426-30.

12 Richardson JR, Leadbetter GW Jr. Non-operative treatment of the ruptured bladder. J Urol. 1975 Aug;114(2): 213-6.

13 Osman Y, El-Tabey N, Mohsen T, El-Sherbiny M. Nonoperative treatment of isolated posttraumatic intraperitoneal bladder rupture in children - is it justified? J Urol. 2005 Mar;173(3):955-7.

14 Hayakawa M, Tuchiya K, Hoshino H, Gando S. Non-operative management of a blunt traumatic intraperitoneal bladder rupture as damage control after a severe pelvic fracture. JJAAM. 2007;18(1):23-6.

15 Geng JH, Chang HC, Chung SD, Chen PH, Chiu B, Tsai CY, et al. Nonoperative treatment for intraperitoneal bladder rupture. Urol Sci. 2014 Jun;25(2):70-2. 


\section{Case Reports in Acute Medicine}

Case Rep Acute Med 2019;2:18-24

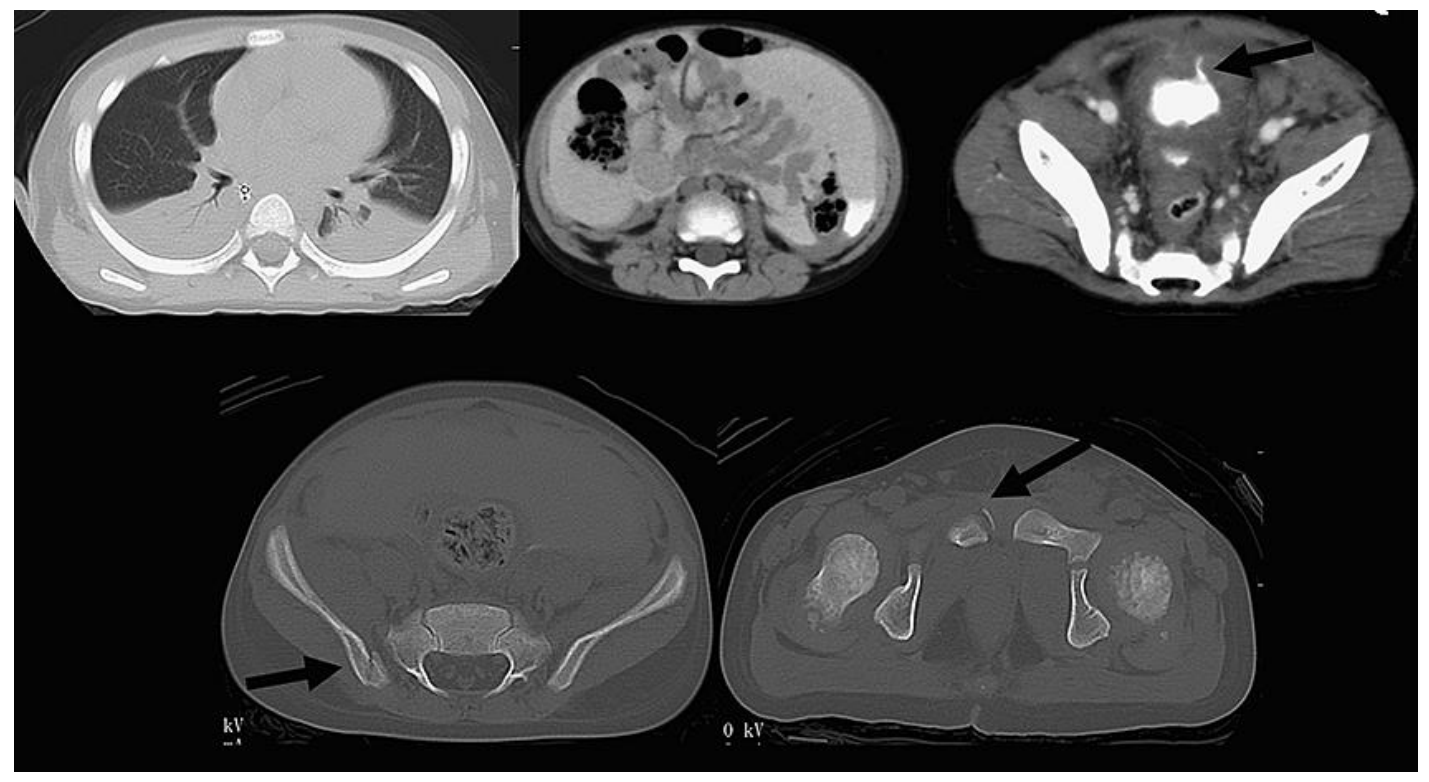

Fig. 1. Chest and abdominal computed tomography at arrival.

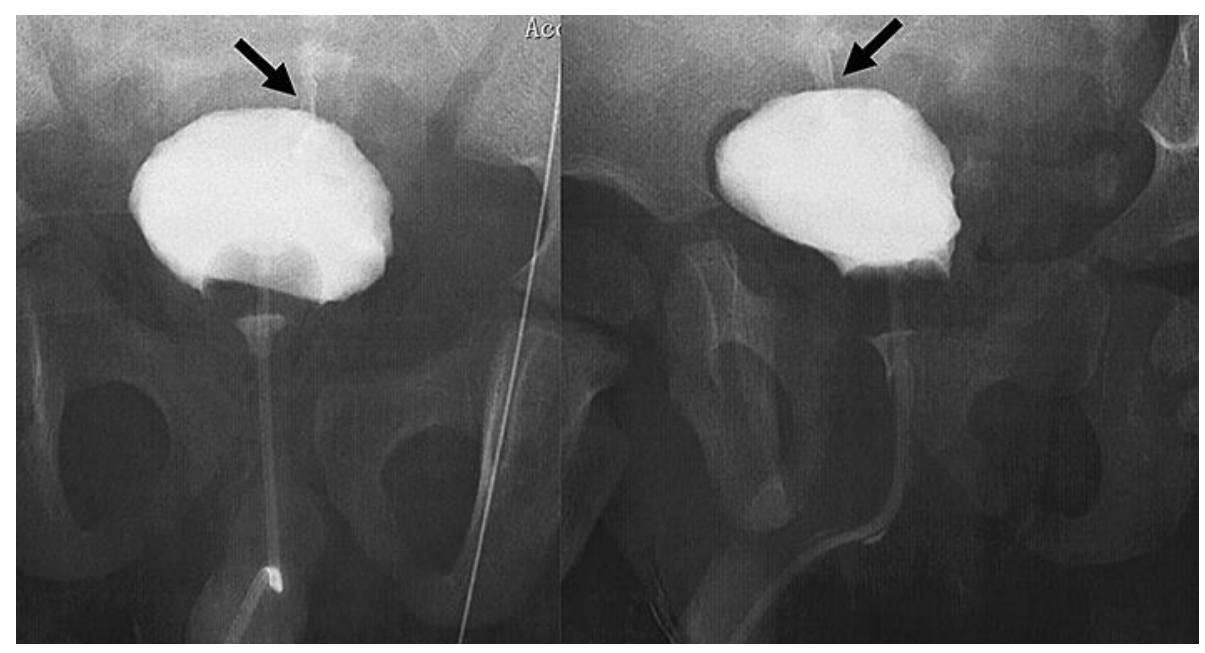

Fig. 2. Cystography. 
Yogo et al.: Successful Conservative Treatment of Intraperitoneal Bladder Rupture in a Child

Table 1. Case series of nonoperated intraperitoneal bladder rupture in pediatric patients caused by blunt trauma

\begin{tabular}{llccllc}
\hline $\begin{array}{l}\text { Refer- } \\
\text { ence }\end{array}$ & $\begin{array}{l}\text { Pa- } \\
\text { tient } \\
\text { No. }\end{array}$ & $\begin{array}{l}\text { Age, } \\
\text { years }\end{array}$ & Sex & $\begin{array}{l}\text { Other } \\
\text { abdominal } \\
\text { organ injury }\end{array}$ & Treatment & $\begin{array}{c}\text { Compli- } \\
\text { cations }\end{array}$ \\
\hline $\begin{array}{l}\text { Osman } \\
\text { et al. }\end{array}$ & 1 & 4 & F & none & $\begin{array}{l}\text { urethral (9 days) and percutaneous } \\
\text { peritoneal drainage (4 days) }\end{array}$ & no \\
\cline { 2 - 7 } & 2 & 13 & M & none & $\begin{array}{l}\text { suprapubic (10 days) and } \\
\text { percutaneous peritoneal drainage } \\
\text { (1 day) }\end{array}$ & no \\
\cline { 2 - 7 } & 3 & 3 & F & none & $\begin{array}{l}\text { urethral (14 days) and percutaneous } \\
\text { peritoneal drainage (3 days) }\end{array}$ & no \\
\cline { 2 - 7 } & 4 & 1 & F & none & $\begin{array}{l}\text { urethral (14 days) and percutaneous } \\
\text { peritoneal drainage (2 days) }\end{array}$ & no \\
\hline $\begin{array}{l}\text { Present } \\
\text { study }\end{array}$ & 5 & 3 & M & none & $\begin{array}{l}\text { urethral (12 days) and percutaneous } \\
\text { peritoneal drainage (4 days) }\end{array}$ & no \\
\hline
\end{tabular}

